\title{
Respiratory failure and sleep-disordered breathing in late-onset Pompe disease: a narrative review
}

\author{
Neeraj Mukesh Shah ${ }^{1,2,3}$, Lakshya Sharma ${ }^{1,4}$, Santhosh Ganeshamoorthy ${ }^{1,4}$, Georgios Kaltsakas ${ }^{1,2,3}$ \\ ${ }^{1}$ Lane Fox Respiratory Service, St. Thomas' Hospital, Guy's and St Thomas' NHS Foundation Trust, London, UK; ${ }^{2}$ Lane Fox Clinical Respiratory \\ Physiology Centre, Guy's and St Thomas' NHS Foundation Trust, London, UK; ${ }^{3}$ Centre for Human and Applied Physiological Sciences (CHAPS), \\ King's College London, London, UK; ${ }^{4}$ Faculty of Life Sciences and Medicine, King's College London, London, UK \\ Contributions: (I) Conception and design: NM Shah, G Kaltsakas; (II) Administrative support: NM Shah, G Kaltsakas; (III) Provision of study \\ materials or patients: NM Shah, L Sharma, S Ganeshamoorthy; (IV) Collection and assembly of data: NM Shah, L Sharma, S Ganeshamoorthy; (V) \\ Data analysis and interpretation: All authors; (VI) Manuscript writing: All authors; (VII) Final approval of manuscript: All authors. \\ Correspondence to: Dr. Georgios Kaltsakas. Lane Fox Respiratory Unit, St Thomas' Hospital, Westminster Bridge Road, London, SE1 7EH, UK. \\ Email: Georgios.kaltsakas@gstt.nhs.uk.
}

\begin{abstract}
Late-onset Pompe disease (LOPD) is a rare autosomal recessive glycogen storage disease that results in accumulation of glycogen in muscle cells causing muscular weakness. It causes a progressive proximal myopathy, accompanied by respiratory muscle weakness, which can lead to ventilatory failure. In untreated LOPD, the most common cause of death is respiratory failure. Patients suffering from respiratory compromise may present with symptoms of sleep-disordered breathing (SDB) before overt signs of respiratory failure. Diaphragm weakness leads to nocturnal hypoventilation, which can result in sleep disruption. Both subjective and objective sleep quality can be impaired with associated excessive daytime sleepiness (EDS). Health-related quality of life worsens as sleep disturbance increases. The mainstay of treatment for SDB and respiratory failure in LOPD is non-invasive ventilation (NIV), which aims to ensure adequate ventilation, particularly during sleep, and prevent acute hypercapnic failure. These patients are at risk of acute deterioration due to lower respiratory tract infections; effective secretion clearance and vaccination against common pathogens is an important facet of care. Whilst disease-modifying enzyme replacement therapy (ERT) delays progression of locomotor dysfunction and prolongs life, its effect on respiratory function and SDB remains unclear. There are no data demonstrating the impact of ERT on sleep quality or SDB.
\end{abstract}

Keywords: Pompe disease; glycogen storage disease type II (GSDII); sleep-disordered breathing (SDB); ventilatory failure; respiratory muscle function; non-invasive ventilation (NIV)

Submitted Jun 12, 2020. Accepted for publication Sep 01, 2020.

doi: $10.21037 /$ jtd-cus-2020-007

View this article at: http://dx.doi.org/10.21037/jtd-cus-2020-007

\section{Introduction}

Pompe disease, or glycogen storage disease type II (GSDII), or acid maltase deficiency, is a rare autosomal recessive disease caused by a deficiency of the lysosomal enzyme acidalpha glucosidase (GAA). This leads to an accumulation of glycogen in smooth, skeletal and respiratory muscles, and cardiac myocytes. Depending upon the residual GAA activity, it manifests in one of two forms. Infantile onset Pompe disease (IOPD), caused by absent GAA, presents with cardiomyopathy, respiratory failure and/or muscle hypotonia within the first year of life (1). These patients are unlikely to survive beyond 18 months (2). Late-onset Pompe disease (LOPD), caused by reduced rather than absent GAA, presents with a milder form, any time from 1 year to adulthood. Although milder, LOPD is progressive and can lead to severe disability and respiratory insufficiency (3). In contrast to IOPD, which is characterized by severe cardiomyopathy, less than $10 \%$ of LOPD patients suffer 
from significant cardiovascular dysfunction (4-7). LOPD has an estimated prevalence of 3.9 per million (8). This review will focus on the pathophysiology, clinical presentation and treatment of respiratory insufficiency and sleep-disordered breathing (SDB) in LOPD.

We present the following article in accordance with the Narrative Review reporting checklist (available at http:// dx.doi.org/10.21037/jtd-cus-2020-007).

\section{Methods}

Literature for this narrative was identified using the following terms in Medline and Embase: "adult", "lateonset", "Pompe", "acid maltase", "glycogen storage disease type II", "respiratory" and "pulmonary". There were no restrictions on dates or study design. English language articles were included.

\section{Epidemiology}

LOPD appears to be evenly distributed between males and females (8-11). Median age at diagnosis is 38 years, while median age at death is 56 years (10). Most patients will present with a lower limb girdle and truncal muscle weakness pattern (12). One-third of patients present with respiratory symptoms as their first manifestation of the illness (8). Approximately half will suffer respiratory involvement during the course of their illness $(11,12)$ and $30-40 \%$ of patients will require treatment with ventilation $(8,9,11,13-15)$, of which the majority will receive noninvasive ventilation (NIV). Importantly, in untreated LOPD, the most common cause of death is respiratory failure $(16,17)$.

\section{Pathophysiology of LOPD}

In healthy individuals, glycogen degradation takes place via two pathways: a cytoplasmic path and a lysosomal path (Figure 1). Glycogen is deposited in lysosomes by autophagic vacuoles, where acid maltase $(\alpha-1,4$-glucosidase, or GAA) hydrolyses it to glucose-1-phosphate. This is then isomerised to glucose-6-phosphate, which is then dephosphorylated to release free glucose, which can exit the cell. In LOPD, mutations in the GAA locus (chromosome $17 \mathrm{q} 25.2-\mathrm{q} 25.3$ ) result in defective acid maltase, which is unable to hydrolyse glycogen. Glycogen therefore builds up in the lysosomes, predominantly in muscle tissue (skeletal, smooth and cardiac) (18). The cytoplastic pathway remains unaffected in LOPD. Biopsies of the arrector pili muscle of LOPD patients have demonstrated that glycogen remains deposited in the lysosomes (glycogenosomes) associated with space-occupying autophagic vacuoles, in fibroblasts of endomysial capillaries and the smooth muscle cells of intramuscular arterioles and small arteries (19). The progressive accumulation of glycogen eventually leads to rupture of the lysosome, which causes leakage of hydrolytic material into the cytoplasm of the myocytes, impairing their contractile function (20). Although classically described as a condition causing proximal myopathy and respiratory muscle weakness, a systematic review of data from clinical trials has demonstrated that LOPD is a multi-system condition affecting the neurological, vascular, cardiac, ophthalmological, gastrointestinal and genitourinary systems, as well as the musculoskeletal and respiratory systems (21).

Respiratory failure in LOPD is classically attributed to accumulation of glycogen in the respiratory skeletal musculature, causing weakness; the diaphragm appears to be affected most severely. To understand why diaphragm weakness leads to respiratory failure, we can use the loadcapacity-drive framework (22). Separately or in unison, reduced respiratory muscle capacity, reduced neural respiratory drive and increased load on the respiratory system will result in hypoventilation (Figure 2).

Respiratory muscle capacity is a measure of inspiratory respiratory muscle strength and endurance. In LOPD, glycogen accumulation in the respiratory skeletal muscle cells impairs their contractile function, leading to respiratory muscle weakness. As the most significant contributor to inspiration, a decrease in diaphragm contractility will lead to reduced muscle capacity and resultant hypoventilation.

Respiratory load is the combination of resistive load (airways resistance to airflow), elastic load (inversely proportional to compliance) and threshold load (intrinsic positive end-expiratory pressure). In LOPD, cough effectiveness is diminished. An effective cough requires an intact inspiratory phase in which the diaphragm and external intercostal muscles will contract, creating a negative pressure around the lung. This forces air into the lung, equalising the pressure and stimulating glottis closure. This requires effective bulbar function. This phase is followed by an expiratory phase, in which expiratory muscles will contract to increase the pressure inside the lung, opening the glottis and forcing air out through the larynx. This requires effective expiratory muscles (22). LOPD causes weakened inspiratory and expiratory muscles leading to 


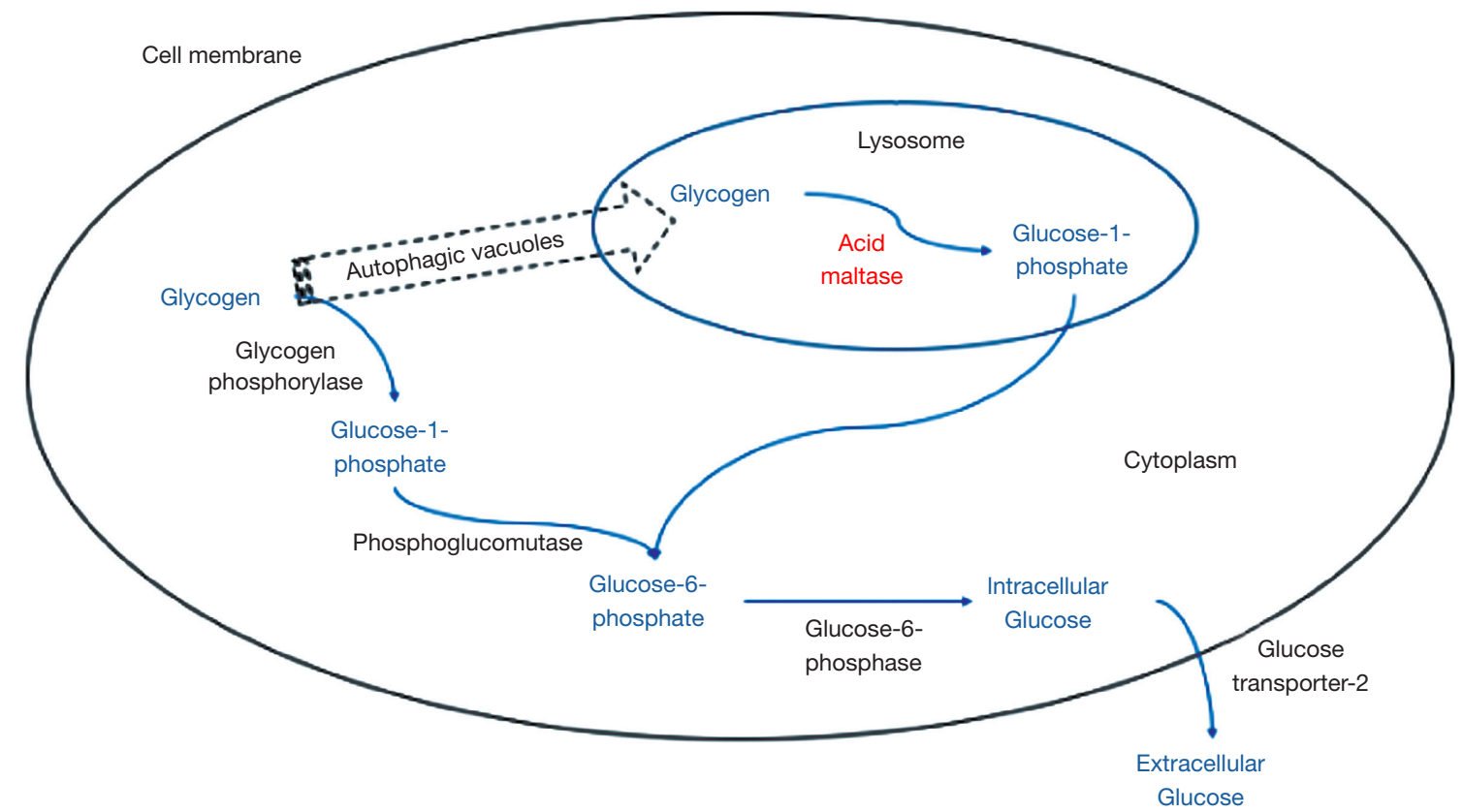

Figure 1 Cellular processing of glycogen and the role of acid maltase in the conversion of glycogen to intracellular glucose.

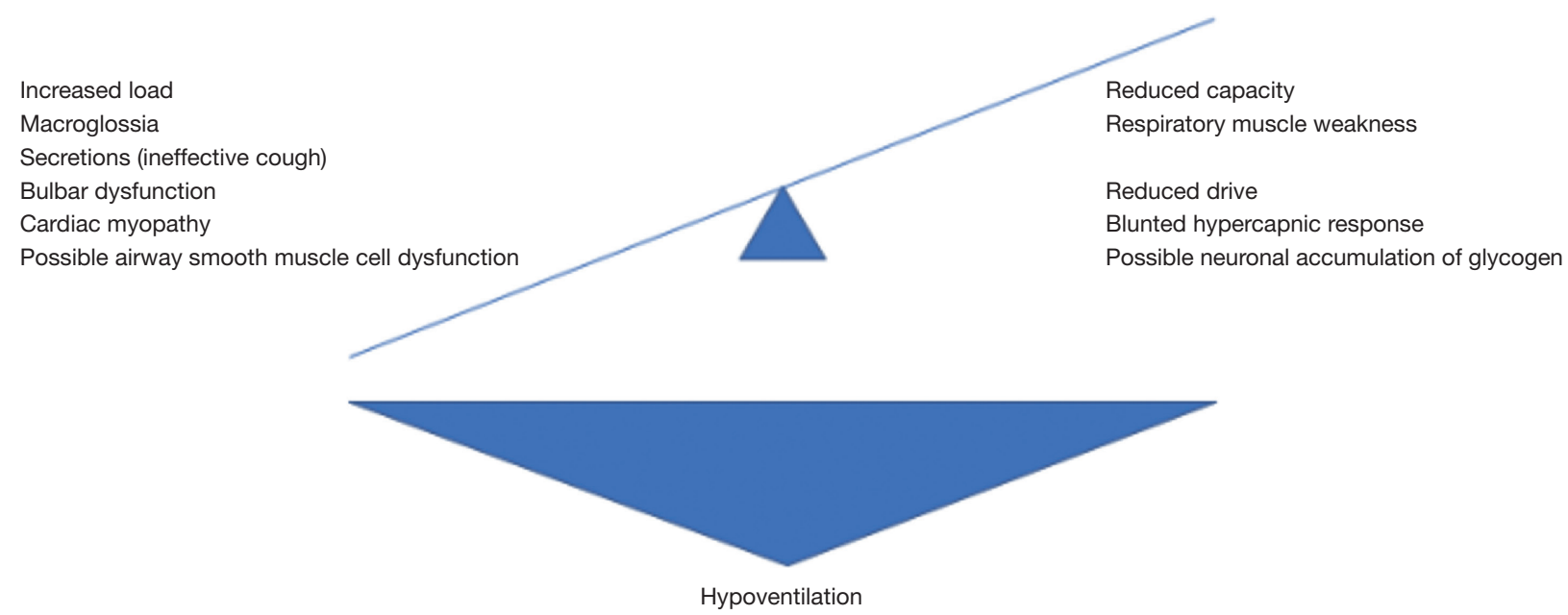

Figure 2 The effect of pathophysiological changes of LOPD on load-capacity-drive and their contribution to the development of hypoventilation. LOPD, late-onset Pompe disease.

an ineffective cough. Case reports also suggest LOPD can cause bulbar dysfunction (23-25). In a cohort of LOPD patients, those who did not require daytime ventilatory support had mean cough peak of $225 \mathrm{~L} / \mathrm{min}$, while those that required daytime support has mean cough peak flow of $84 \mathrm{~L} / \mathrm{min}$ (26). Cough peak flow between 160 and $270 \mathrm{~L} / \mathrm{min}$ has been demonstrated in Duchenne muscular dystrophy to be associated with reduced cough effectiveness during a respiratory tract infection (27). Thus, almost all LOPD patients are likely to suffer from a less effective cough during intercurrent lower respiratory tract infection. Intercurrent infections can be particularly troublesome; excessive secretions and atelectasis will increase the resistive load, increasing the likelihood of ventilatory failure.

Clinical and radiological assessment suggest that most LOPD patients, including those with early features of 
the disease, have tongue muscle weakness and associated macroglossia, due to glycogen accumulation, and that this can be independent of any impact on the facial muscles $(28,29)$. This may cause airway obstruction, particularly during sleep, increasing resistive load.

Neural respiratory drive is the control of the rate and work of breathing from the respiratory centre in the medulla, in response to $\mathrm{pH}$ and $\mathrm{PaCO}_{2}$. This control is transmitted via the spinal cord. Without adequate drive and transmission of neural information to the respiratory muscles, there will be an inadequate ventilatory response to increased $\mathrm{PaCO}_{2}$ and subsequent ventilatory failure. Patients with LOPD can present with a hypercapnia that is out of proportion with the degree of respiratory muscle weakness. A single study has demonstrated that LOPD patients demonstrate an inadequate increase in the occlusion pressure during the first $0.1 \mathrm{~s}$ of inspiration $\left(\mathrm{P}_{0.1}\right)$ in response to rising $\mathrm{CO}_{2}(30) . \mathrm{P}_{0.1}$ is a measure of respiratory drive $(31,32)$. Although an isolated study, it is consistent with other reports of diminished hypercapnic response in patients with neuromuscular weakness $(33,34)$. This blunted response to hypercapnia, which is effectively an inadequate increase in respiratory drive will result in an inadequate increase in alveolar ventilation and therefore progression to hypercapnic failure, particularly during acute illness.

There is increasing interest in a causative contribution from respiratory neuronal accumulation in LOPD (35), however a recent study demonstrated no difference in diaphragm motor evoked potentials between LOPD patients and healthy controls (36). In addition, there is emerging evidence for airway smooth muscle cell involvement, although this has only been demonstrated in animal models and IOPD so far (37). In response to these pathophysiological changes, to prevent respiratory muscle fatigue, these patients may adopt a rapid shallow breathing pattern (38). While this may be energy-conserving, it does not provide adequate ventilation and will eventually lead to ventilatory failure.

\section{Investigating respiratory function in LOPD}

LOPD presents insidiously with non-specific symptoms. The diagnosis of LOPD often occurs several years after the onset of the first symptoms (39). Patients will initially report complaints suggestive of progressively reducing muscle strength, such as a difficulty with physical exercise, difficulty climbing stairs or standing from a chair. This is likely to be associated with muscle aches and tiredness. A small proportion will report respiratory symptoms such as breathlessness or frequent chest infections and symptoms of SDB such as snoring, daytime headaches and excessive daytime somnolence. They may also report weight loss, due to difficulty swallowing (40). Clinical examination is likely to reveal features of proximal myopathy (waddling gait, Gowers' manoeuvre, lumbar hyperlordosis, weakness of the shoulder girdle muscles, scapula winging). Arterial blood gas analysis may demonstrate daytime hypercapnia in patients with advanced disease, although this is more likely to be present during sleep in patients presenting earlier (41).

LOPD can be screened for using a dried blood spotbased GAA activity assay, which has a high sensitivity and specificity for Pompe when used in patients with clinical features suspicious of Pompe $(42,43)$. The diagnosis is then confirmed by GAA activity testing in fibroblasts, or genetic testing for GAA mutations. Previously, muscle biopsy to identify glycogen accumulation in lysosomes was used to diagnose LOPD, but this has largely been replaced by GAA activity testing (44).

Pulmonary function tests are a key component of the evaluation of a patient with LOPD, and can be used to predict the need for nocturnal or 24-hour ventilation (45). The relationship between vital capacity (VC) and respiratory muscle weakness is important to consider, when interpreting pulmonary function tests in LOPD. De Troyer et al. (46) demonstrated a curvilinear relationship between VC and maximal inspiratory pressure (MIP). In mild disease (with preserved MIP 60-80\%), changes in MIP will not result in significant changes in $\mathrm{VC}$, while in more advanced disease (MIP <40\%), large changes in VC will be attributed to small changes in MIP. It is therefore important to measure both respiratory muscle strength and lung volumes, and also important to appreciate this curvilinear relationship when interpreting data on neuromuscular disease, including LOPD.

Spirometry tends to demonstrate a restrictive defect, more pronounced in males (13), with VC reported as approximately $30 \%$ of predicted value at the time of initiation of home mechanical ventilation (41). A patientlevel data meta-analysis has demonstrated that forced $\mathrm{VC}$ (FVC) is associated with numerous LOPD outcome measures and the progression in FVC is associated with changes in exercise tolerance, peripheral muscle strength and health-related quality of life (47).

Respiratory muscle strength, evaluated by the MIP and maximal expiratory pressure (MEP) are also reduced in 
LOPD, compared with healthy controls (36). MIP and MEP can be reduced to over $50 \%$ of predicted values $(13,41,48)$ and this reduction is progressive, with a $3-4 \%$ annual decline in MIP and MEP (13).

Diaphragm weakness is formally assessed using invasive measures of transdiaphragmatic pressure $(49,50)$, and has been demonstrated to be more pronounced in LOPD compared to healthy controls $(36,51)$. This tool is not widely available; a useful non-invasive surrogate for assessing diaphragmatic weakness is the change in spirometric measurements from the sitting to supine position (52). In healthy individuals, a healthy diaphragm will prevent excessive cephalad movement of the abdominal viscera when supine, preserving the lung volume. If the diaphragm is weakened, it will not prevent compression of lung tissue by the abdominal viscera, resulting in a reduction in lung volume (53). In individuals without any restrictive impairment, the difference in FVC or slow VC from sitting to supine is usually $5-10 \%$ (54) and no more than $15-20 \%$, while a fall of more than $30 \%$ is a marker of diaphragmatic weakness/paralysis (55). In LOPD, FVC reduces from sitting to supine by more than $25 \%$ $(13,48)$. It is important to assess supine FVC, as patients with diaphragmatic weakness may have a normal sitting FVC (56).

Diaphragm dysfunction could also be assessed by dynamic respiratory testing (57) as well as CT and MRI imaging (58,59). MRI data have demonstrated that the pattern of respiratory muscle weakness is predominantly diaphragmatic, with sparing of intercostal muscles, as measured by antero-posterior chest expansion (59).

Neural respiratory drive can be measured as a marker of the work of breathing using various techniques, including electromyogram of the diaphragm (60) or parasternal muscles $(61,62)$, or the mouth occlusion pressure at 0.1 second of tidal breathing $\left(\mathrm{P}_{0.1}\right)$ (32). $\mathrm{P}_{0.1}$ is decreased in LOPD patients compared to healthy controls demonstrating reduced respiratory drive (63).

Fatigue is an important feature of LOPD that has an impact on quality of life and warrants assessment (64). Patients with LOPD had a higher fatigue severity score (FSS) than control, and those who reported sleep disturbance or were receiving ventilatory support had higher FSS $(65,66)$.

\section{Sleep disturbance in LOPD}

Diaphragm weakness leads to nocturnal hypoventilation, which can result in sleep disruption and excessive daytime sleepiness (EDS) (67). Although sleep disruption is relatively common in LOPD, few studies have been published on its prevalence or effects.

A cohort of LOPD patients receiving enzyme replacement therapy (ERT) reported reduced subjective sleep quality [measured as Pittsburgh Sleep Quality Index (PSQI)] in $45 \%$ of patients (66). Sleep quality was inversely proportional to exercise tolerance (6-minute walking distance test) and motor performance (Rotterdam Nine-Item Handicap Scale). EDS was reported by $25 \%$ of patients and significant fatigue (measured as Fatigue Severity Scale) was reported by $72 \%$. Importantly, healthrelated quality of life (reported as the physical and mental component summary scales of the SF-36 questionnaire) was inversely proportional to PSQI. Half of this cohort were receiving home mechanical ventilation. There were no significant differences in the PSQI between those who were receiving nocturnal ventilation and those who were not, suggesting that the sleep disturbance observed in this cohort was independent of the need for a ventilator. Unsurprisingly, patients receiving daytime ventilation in addition to nocturnal ventilation reported worse sleep quality, more fatigue and lower quality of life scores than those receiving nocturnal ventilation alone. In a cohort of LOPD patients receiving inspiratory muscle training (IMT), sleep quality was assessed before and after the intervention. Baseline PSQI demonstrated poor subjective sleep quality and this did not change after IMT (68).

Objective sleep quality, assessed by polysomnography, was evaluated in a cohort of LOPD patients during a hospital attendance. SDB, assessed by the respiratory disturbance index (a composite of more than 10 episodes of apnoea, hypopnoea and desaturation per hour of sleep), was present in $48 \%$ of patients, and this was independently associated with diaphragm weakness (69). SDB occurred almost exclusively during rapid eye movement (REM) sleep, and there was no correlation with body mass index or obstructive sleep apnoea (OSA) symptoms. Progression from REM-sleep hypopnoeas to continuous nocturnal hypoventilation was significantly associated with declining inspiratory VC (69), demonstrating that the degree of SDB is associated with the degree of respiratory compromise. Although there are no screening tools for SDB validated for LOPD, the Sleep-Disordered Breathing in Neuromuscular Disease Questionnaire (SiNQ-5) is validated for use in patients with diaphragm paralysis (70) and could therefore be used to screen for SDB in LOPD. 


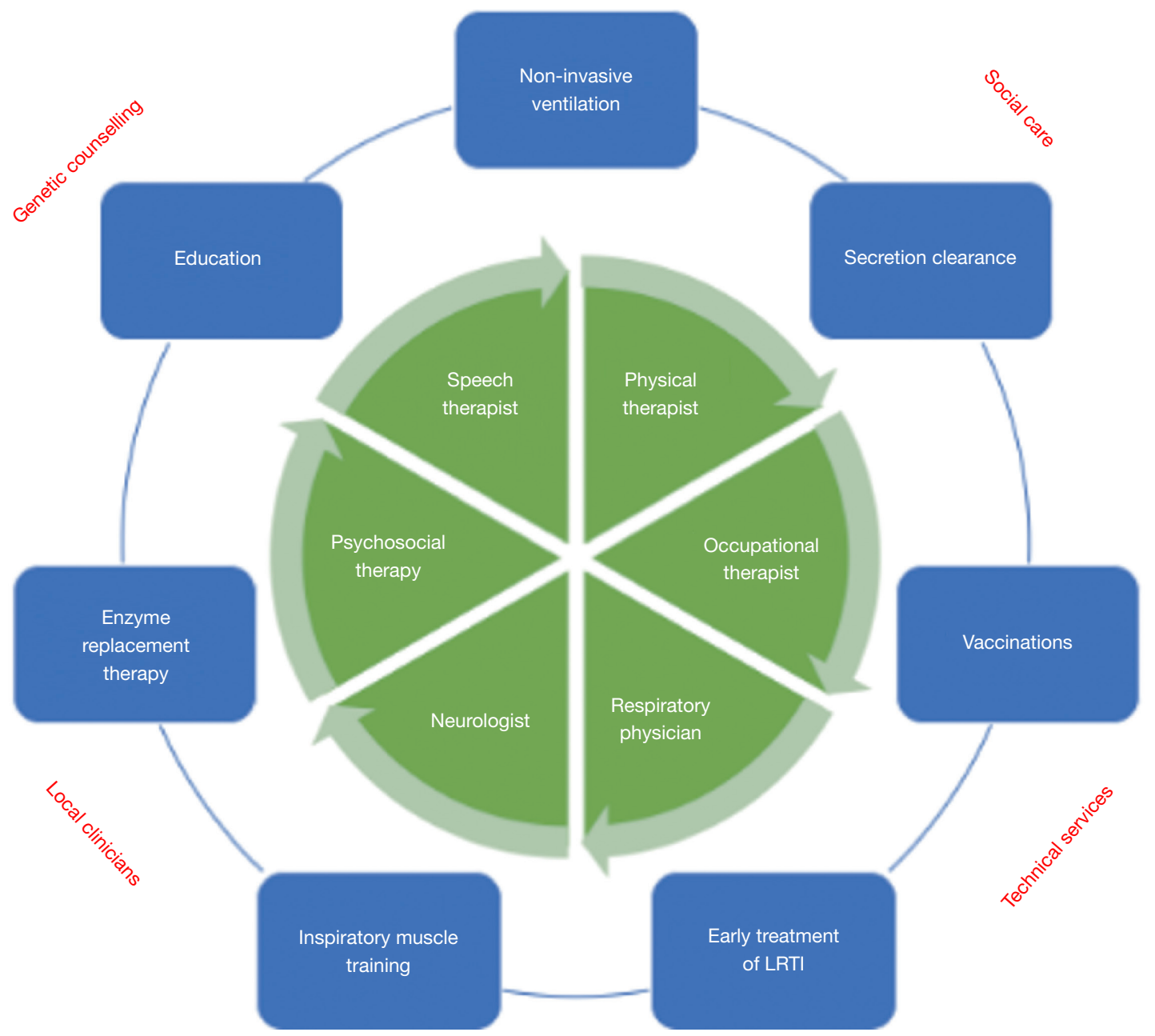

Figure 3 Components of the multidisciplinary team caring for a patient with LOPD and the roles they perform. LOPD, late-onset Pompe disease.

Tongue muscle weakness $(28,29)$ may also contribute to SDB by causing airway obstruction in sleep. A case report of a patient who died following weaning failure reported the presence of severe OSA, and on autopsy, profound replacement of tongue muscle by fibrofatty tissue (71). In addition, a recent case report has demonstrated that effective treatment of LOPD with ERT allowed the withdrawal of ventilator therapy for OSA (72). It is unclear whether LOPD contributes to OSA as there are no reports of upper airway collapsibility during sleep in LOPD patients.

\section{Management of respiratory failure and SDB}

Respiratory management strategies for LOPD aim to delay deterioration of respiratory function and prevent death due to lower respiratory tract infections. Key elements of the management of LOPD by the respiratory team are displayed in Figure 3.

The cornerstone of management of respiratory failure and SDB in LOPD is NIV. NIV is used to treat nocturnal hypoventilation and as the disease progresses, daytime hypercapnia. Although there is an absence of literature demonstrating the long-term clinical value of NIV specifically in LOPD, the use of domiciliary NIV in neuromuscular disorder patients with chronic hypercapnic failure has a strong evidence base and is well established practice (73). Given the lack of literature in LOPD specifically, treatment recommendations for NIV are based on expert consensus. NIV is recommended when the patient exhibits physiologic evidence of nocturnal hypoventilation, 
such as significant daytime hypercapnia and nocturnal oxygen desaturation, or symptoms suggestive of nocturnal hypoventilation, such as morning headache, dyspnoea or fatigue (74).

Mellies and colleagues demonstrated that initiation of NIV in LOPD patients normalised overnight gas exchange and improved subjective sleep disturbance (41). Importantly, NIV appears to improve markers of SDB such as the apnoea-hyponoea index, $4 \%$ overnight desaturation index, mean oxygen and carbon dioxide saturations and time spent below $90 \%$ oxygen saturation $(66,75,76)$. Despite this, polysomnographic markers of sleep quality (sleep efficiency, arousal index, percentage of N3 and REM sleep) (76) and subjective measures of sleep quality (PSQI) and fatigue (Fatigue Severity Scale) (66) did not improve following introduction of NIV. Longitudinal studies of the effect of NIV on LOPD have not been conducted; it is therefore difficult to comment on the value of NIV on long-term outcomes but there is clear evidence from these observational studies that it improves overnight gas exchange.

Occasionally, a patient will require long-term invasive ventilation via trachesotomy. This may be because NIV is contra-indicated, if NIV has failed to improve gas exchange, the cough remains ineffective despite artificial assistance, or the airway cannot be protected (77). In the case of ineffective cough, a mini-tracheostomy could be used to avoid invasive ventilation (78).

An important element of respiratory care for LOPD patients is ensuring effective secretion clearance. A wide array of secretion clearance techniques is available, depending upon whether the patient needs support in mobilising their secretions from distal to proximal airways, or expelling secretions from the proximal airways (79). None of the techniques have been specifically investigated in LOPD, but the pattern of cough muscle weakness is similar to the congenital muscular dystrophies and so a management approach similar to that adopted in muscular dystrophy is likely to be effective (80).

IMT frequently features in the management of neuromuscular disease patients, despite equivocal evidence for its use (81). In LOPD, IMT appears to have a beneficial effect on MIP $(68,82,83)$. This is of particular relevance in LOPD. MIP is a measure of global inspiratory muscle function, and as the diaphragm is the most significant contributor to inspiration, MIP can be viewed as an indirect marker of diaphragmatic function (84). However, despite the perceived improvement in diaphragmatic function, this did not result in an improvement in spirometry, gas exchange, sleep quality or health-related quality of life $(68,83)$. MIP increased from $38 \%$ predicted to $50 \%$ predicted, while baseline sitting FVC was $65 \%$ predicted. Based on the curvilinear relationship between VC and MIP (46), it is unsurprising that the improvement in MIP did not result in an improvement in FVC, as the MIP was not improved enough for a significant FVC change to manifest. The existing evidence for IMT comes from observational studies; there is a need for randomised studies to determine the value of IMT on long-term LOPD outcomes, before definite recommendations can be made.

Other important measures in the respiratory management of a LOPD patient is to ensure the patient is up to date with influenza and pneumococcal vaccinations, and to maintain high vigilance and treat lower respiratory tract infections early and aggressively (44). LOPD patients have reduced respiratory reserve to respond to lower respiratory tract infections and so are at risk of acute respiratory failure (77). In the LOPD patient who suffers from cardiomyopathy, cardiology input is also essential to slow the deterioration in their cardiac function.

\section{Enzyme replacement therapy}

ERT is now offered to patients with LOPD. Recombinant alglucosidase alfa is believed to replace deficient lysosomal GAA activity to improve muscle function. Systematic reviews have reported that ERT is effective at preventing deterioration in patients with LOPD $(85,86)$, although the data specifically on respiratory function are limited. In addition, no studies investigating the effect of ERT on sleep outcomes have been identified. A Cochrane review on the effect of ERT on LOPD is awaited (87). A recent review of the impact of ERT on pulmonary outcomes in various lysosomal storage diseases was unable to provide any conclusive insights due to the dearth and variability of the data available (88).

The majority of data on the value of ERT on respiratory function is found in observational registry studies of patients receiving ERT (Table 1). The majority reported unchanged respiratory function, usually measured as upright FVC following varying periods of ERT use (89-92), with only one study reporting an improvement in FVC with ERT use (93). The impact of ERT on the need for ventilation was more variable; one study reported that ERT delayed the requirement for ventilation (89), while others reported no effect on the need for ventilation $(90,94)$. 
Table 1 A summary of pharmacological studies in LOPD that reported respiratory outcome measures

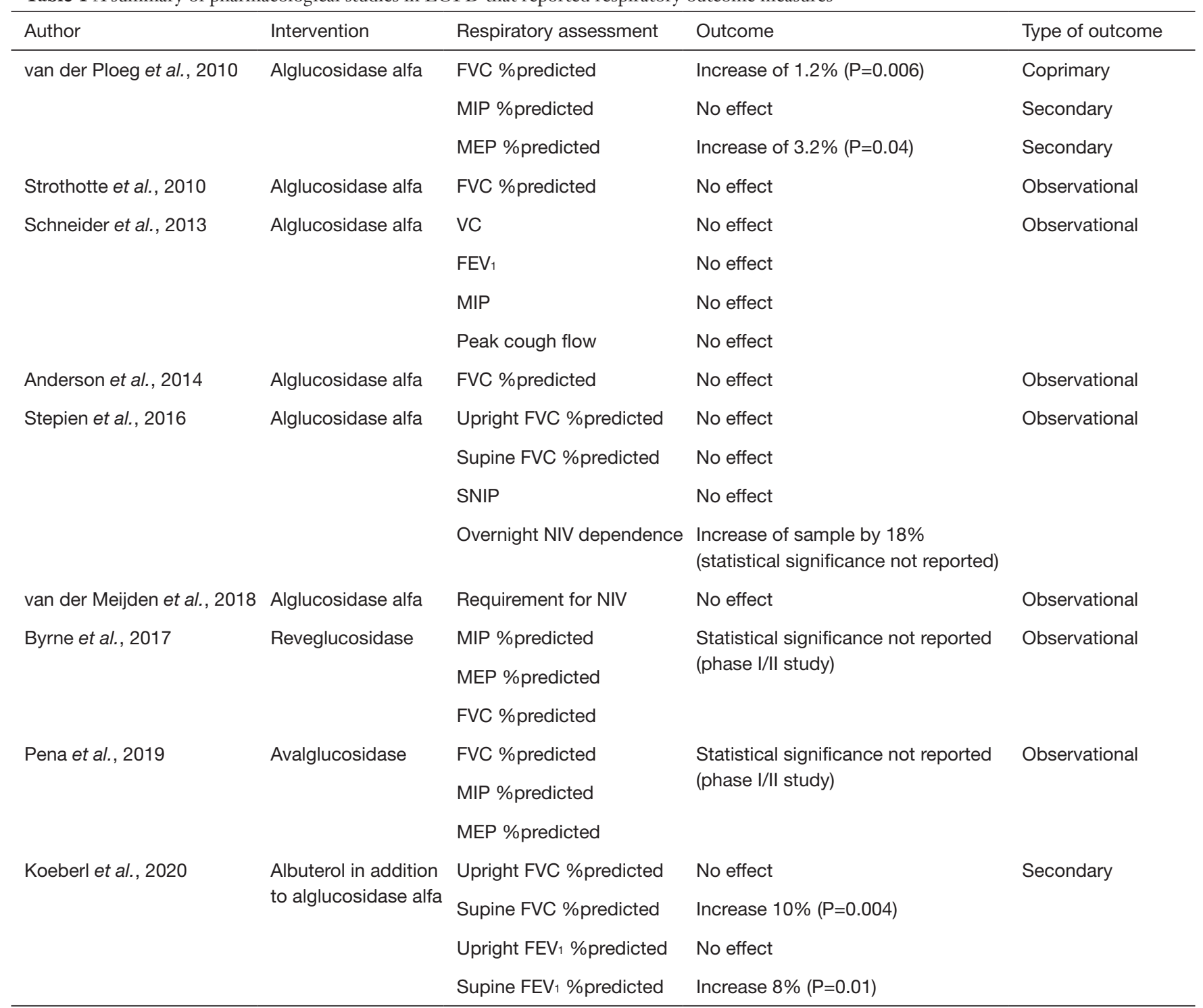

LOPD, late-onset Pompe disease; FVC, forced vital capacity; MIP, maximal inspiratory pressure; MEP, maximal expiratory pressure; VC, vital capacity; FEV 1 , forced expiratory volume in 1 second; NIV, non-invasive ventilation.

Limited randomised controlled studies have been conducted to investigate ERT in LOPD, and a single study included pulmonary endpoints. The Late-Onset Treatment Study (LOTS) compared patients receiving bi-weekly intravenous alglucosidase alfa with placebo, investigating \% predicted upright FVC as a coprimary endpoint (95). They reported that the treatment arm did not have any deterioration in \%predicted upright FVC whereas the placebo arm did. A recent randomised trial investigated the impact of the addition of a beta-agonist, albuterol, on patients receiving ERT. This reported that albuterol resulted in an increase in supine FVC and forced expiratory volume in 1 second $\left(\mathrm{FEV}_{1}\right)$ when compared to ERT alone, although these were secondary endpoints (96). This result was unexpected by the authors of the study, but may reflect a beneficial effect on airway smooth muscle cells; this remains to be elucidated. Safety and efficacy studies for two novel ERT, reveglucosidase alfa (97) and avalglucosidase alfa (98), have reported no deterioration in \%predicted MIP, MEP of FVC during the follow-up period. Thus, there may be some benefit from ERT on pulmonary function, but without more randomised studies specifically investigating 
pulmonary function, it is difficult to make any conclusive recommendations. Nevertheless, the value of ERT is recognised on other non-respiratory elements of LOPD and so LOPD patients presenting to the respiratory clinic are likely to be receiving ERT during the course of their disease.

\section{Summary}

LOPD is a rare glycogen storage disease that can lead to SDB and ventilatory failure. Glycogen accumulation in myocyte lysosomes leads to respiratory muscle fatigue, most pronounced in the diaphragm. Patients typically present with progressive muscle weakness, but this can be insidious and it can take many years for a diagnosis of LOPD to be confirmed. Investigations are likely to reveal inspiratory muscle weakness. Patients will suffer from significant sleep disturbance and SDB almost exclusively during REM sleep. The cornerstone of treatment for ventilatory failure and SDB in LOPD is domiciliary NIV, however over $50 \%$ of LOPD patients will not receive NIV. Although pharmacological agents are available for LOPD, there are little data to demonstrate any benefit on respiratory or sleep outcomes. There is a need to conduct randomised studies and analyse observational registry cohorts to determine the impact of pharmacological agents on respiratory function and SDB.

\section{Acknowledgments}

Funding: None.

\section{Footnote}

Provenance and Peer Review: This article was commissioned by the Guest Editor (Joerg Steier) for the series " $5^{\text {th }}$ Clinical Update Sleep" published in Fournal of Thoracic Disease. The article was sent for external peer review.

Reporting Checklist: The authors have completed the Narrative Review reporting checklist. Available at http:// dx.doi.org/10.21037/jtd-cus-2020-007

Conflicts of Interest: All authors have completed the ICMJE uniform disclosure form (available at http://dx.doi. org/10.21037/jtd-cus-2020-007). The series " $5^{\text {th }}$ Clinical Update Sleep" was commissioned by the editorial office without any funding or sponsorship. The authors have no conflicts of interest to declare.

Ethical Statement: The authors are accountable for all aspects of the work in ensuring that questions related to the accuracy or integrity of any part of the work are appropriately investigated and resolved.

Open Access Statement: This is an Open Access article distributed in accordance with the Creative Commons Attribution-NonCommercial-NoDerivs 4.0 International License (CC BY-NC-ND 4.0), which permits the noncommercial replication and distribution of the article with the strict proviso that no changes or edits are made and the original work is properly cited (including links to both the formal publication through the relevant DOI and the license). See: https://creativecommons.org/licenses/by-nc-nd/4.0/.

\section{References}

1. Kishnani PS, Hwu WL, Mandel H, et al. A retrospective, multinational, multicenter study on the natural history of infantile-onset Pompe disease. J Pediatr 2006;148:671-6.

2. van den Hout HM, Hop W, van Diggelen OP, et al. The natural course of infantile Pompe's disease: 20 original cases compared with 133 cases from the literature. Pediatrics 2003;112:332-40.

3. Toscano A, Rodolico C, Musumeci O. Multisystem late onset Pompe disease (LOPD): an update on clinical aspects. Ann Transl Med 2019;7:284.

4. Soliman OI, van der Beek NA, van Doorn PA, et al. Cardiac involvement in adults with Pompe disease. J Intern Med 2008;264:333-9.

5. van der Beek NA, Soliman OI, van Capelle CI, et al. Cardiac evaluation in children and adults with Pompe disease sharing the common c.-32-13T $>\mathrm{G}$ genotype rarely reveals abnormalities. J Neurol Sci 2008;275:46-50.

6. Boentert M, Florian A, Dräger B, et al. Pattern and prognostic value of cardiac involvement in patients with late-onset pompe disease: a comprehensive cardiovascular magnetic resonance approach. J Cardiovasc Magn Reson 2016;18:91.

7. Herbert M, Cope H, Li JS, et al. Severe cardiac involvement is rare in patients with late-onset Pompe disease and the common c.-32-13T $>\mathrm{G}$ variant: implications for newborn screening. J Pediatr 2018;198:308-12.

8. Vanherpe P, Fieuws S, D'Hondt A, et al. Late-onset Pompe disease (LOPD) in Belgium: clinical characteristics and outcome measures. Orphanet J Rare Dis 2020;15:83. 
9. Laforêt P, Laloui K, Granger B, et al. The French Pompe registry. Baseline characteristics of a cohort of 126 patients with adult Pompe disease. Rev Neurol (Paris) 2013;169:595-602.

10. Güngör D, de Vries JM, Hop WCJ, et al. Survival and associated factors in 268 adults with Pompe disease prior to treatment with enzyme replacement therapy. Orphanet J Rare Dis 2011;6:34.

11. Alonso-Pérez J, Segovia S, Domínguez-González C, et al. Spanish Pompe registry: baseline characteristics of first 49 patients with adult onset of Pompe disease. Med Clin (Barc) 2020;154:80-5.

12. Schüller A, Wenninger S, Strigl-Pill N, et al. Toward deconstructing the phenotype of late-onset Pompe disease. Am J Med Genet C Semin Med Genet 2012;160C:80-8.

13. van der Beek NA, van Capelle CI, van der Velden-van Etten KI, et al. Rate of progression and predictive factors for pulmonary outcome in children and adults with Pompe disease. Mol Genet Metab 2011;104:129-36.

14. Hagemans MLC, Hop WJC, Van Doorn PA, et al. Course of disability and respiratory function in untreated lateonset Pompe disease. Neurology 2006;66:581-3.

15. Hagemans ML, Winkel LP, Van Doorn PA, et al. Clinical manifestation and natural course of late-onset Pompe's disease in 54 Dutch patients. Brain 2005;128:671-7.

16. Winkel LP, Hagemans ML, van Doorn PA, et al. The natural course of non-classic Pompe's disease; a review of 225 published cases. J Neurol 2005;252:875-84.

17. Howard RS, Wiles CM, Hirsch NP, et al. Respiratory involvement in primary muscle disorders: assessment and management. QJ Med 1993;86:175-89.

18. Adeva-Andany MM, González-Lucán M, DonapetryGarcía C, et al. Glycogen metabolism in humans. BBA Clin 2016;5:85-100.

19. Katona I, Weis J, Hanisch F. Glycogenosome accumulation in the arrector pili muscle in Pompe disease. Orphanet J Rare Dis 2014;9:17.

20. Faverio P, Stainer A, De Giacomi F, et al. Molecular pathways and respiratory involvement in lysosomal storage diseases. Int J Mol Sci 2019;20:327.

21. Chan J, Desai AK, Kazi ZB, et al. The emerging phenotype of late-onset Pompe disease: a systematic literature review. Mol Genet Metab 2017;120:163-72.

22. Shah NM, Murphy PB. Hypercapnic respiratory failure in non-COPD. In: Heunks L, Demoule A, Windisch W. editors. Pulmonary Emergencies. ERS Monograph. UK: European Respiratory Society Monograph, 2016;74:86-100. 23. Maggi L, Salerno F, Bragato C, et al. Familial adult- onset Pompe disease associated with unusual clinical and histological features. Acta Myol 2013;32:85-90.

24. Hobson-Webb LD, Jones HN, Kishnani PS. Oropharyngeal dysphagia may occur in late-onset Pompe disease, implicating bulbar muscle involvement. Neuromuscul Disord 2013;23:319-23.

25. Karam C, Dimitrova D, Yutan E, et al. Bright tongue sign in patients with late-onset Pompe disease. J Neurol 2019;266:2518-23.

26. Pitts T, Bordelon R, Huff A, et al. Cough effectiveness and pulmonary hygiene practices in patients with Pompe disease. Lung 2019;197:1-8.

27. Bach JR, Ishikawa Y, Kim H. Prevention of pulmonary morbidity for patients with Duchenne muscular dystrophy. Chest 1997;112:1024-8.

28. Dubrovsky A, Corderi J, Lin M, et al. Expanding the phenotype of late-onset Pompe disease: tongue weakness: a new clinical observation. Muscle Nerve 2011;44:897-901.

29. Carlier RY, Laforet P, Wary C, et al. Whole-body muscle MRI in 20 patients suffering from late onset Pompe disease: Involvement patterns. Neuromuscul Disord 2011;21:791-9.

30. De Vito EL, Monteiro SG, Aruj PK. Blunted hypercapnic respiratory drive response in subjects with late-onset Pompe disease. Respiratory Care 2016;61:930.

31. Whitelaw WA, Derenne JP. Airway occlusion pressure. J Appl Physiol (1985) 1993;74:1475-83.

32. Whitelaw WA, Derenne JP, Milic-Emili J. Occlusion pressure as a measure of respiratory center output in conscious man. Respir Physiol 1975;23:181-99.

33. Aruj PK, Monteiro SG, De Vito EL. Analysis of factors associated with chronic hypercapnia in patients with myotonic dystrophy. Medicina 2013;73:529-34.

34. Raurich JM, Rialp G, Llompart-Pou JA, et al. Respiratory $\mathrm{CO} 2$ response in acute cervical spinal cord injury $(\mathrm{CO} 2$ response in spinal cord injury). Spinal Cord 2014;52:39-43.

35. Fuller DD, ElMallah MK, Smith BK, et al. The respiratory neuromuscular system in Pompe disease. Respir Physiol Neurobiol 2013;189:241-9.

36. Spiesshoefer J, Henke C, Kabitz HJ, et al. The nature of respiratory muscle weakness in patients with late-onset Pompe disease. Neuromuscul Disord 2019;29:618-27.

37. McCall AL, Salemi J, Bhanap P, et al. The impact of Pompe disease on smooth muscle: a review. J Smooth Muscle Res 2018;54:100-18.

38. Ambrosino N, Carpene N, Gherardi M. Chronic respiratory care for neuromuscular diseases in adults. Eur Respir J 2009;34:444-51. 
39. Müller-Felber W, Horvath R, Gempel K, et al. Late onset Pompe disease: clinical and neurophysiological spectrum of 38 patients including long-term follow-up in 18 patients. Neuromuscul Disord 2007;17:698-706.

40. Di Iorio G, Cipullo F, Stromillo L, et al. S1.3 Adult-onset Pompe disease. Acta Myologica 2011;30:200-2.

41. Mellies U, Stehling F, Dohna-Schwake C, et al. Respiratory failure in Pompe disease: treatment with noninvasive ventilation. Neurology 2005;64:1465-7.

42. Goldstein JL, Young SP, Changela M, et al. Screening for Pompe disease using a rapid dried blood spot method: experience of a clinical diagnostic laboratory. Muscle Nerve 2009;40:32-6.

43. Winchester B, Bali D, Bodamer OA, et al. Methods for a prompt and reliable laboratory diagnosis of Pompe disease: report from an international consensus meeting. Mol Genet Metab 2008;93:275-81.

44. Kishnani PS, Steiner RD, Bali D, et al. Pompe disease diagnosis and management guideline. Genet Med 2006;8:267-88.

45. Johnson EM, Roberts M, Mozaffar T, et al. Pulmonary function tests (maximum inspiratory pressure, maximum expiratory pressure, vital capacity, forced vital capacity) predict ventilator use in late-onset Pompe disease. Neuromuscular Disorders 2016;26:136-45.

46. De Troyer A, Borenstein S, Cordier R. Analysis of lung volume restriction in patients with respiratory muscle weakness. Thorax 1980;35:603.

47. Berger KI, Kanters S, Jansen JP, et al. Forced vital capacity and cross-domain late-onset Pompe disease outcomes: an individual patient-level data meta-analysis. J Neurol 2019;266:2312-21.

48. Wokke JH, Escolar DM, Pestronk A, et al. Clinical features of late-onset Pompe disease: a prospective cohort study. Muscle Nerve 2008;38:1236-45.

49. Loh L, Goldman M, Davis JN. The assessment of diaphragm function. Medicine (Baltimore) 1977;56:165-9.

50. Mier A, Brophy C, Moxham J, et al. Twitch pressures in the assessment of diaphragm weakness. Thorax 1989;44:990-6.

51. Smith BK, Corti M, Martin AD, et al. Altered activation of the diaphragm in late-onset Pompe disease. Respir Physiol Neurobiol 2016;222:11-5.

52. Fromageot C, Lofaso F, Annane D, et al. Supine fall in lung volumes in the assessment of diaphragmatic weakness in neuromuscular disorders. Arch Phys Med Rehabil 2001;82:123-8.

53. Wade OL, Gilson JC. The effect of posture on diaphragmatic movement and vital capacity in normal subjects with a note on spirometry as an aid in determining radiological chest volumes. Thorax 1951;6:103-26.

54. Allen SM, Hunt B, Green M. Fall in vital capacity with posture. Br J Dis Chest 1985;79:267-71.

55. Laroche CM, Carroll N, Moxham J, et al. Clinical significance of severe isolated diaphragm weakness. Am Rev Respir Dis 1988;138:862-6.

56. American Association of Neuromuscular \& Electrodiagnostic Medicine. Diagnostic criteria for lateonset (childhood and adult) Pompe disease. Muscle Nerve 2009;40:149-60.

57. Smith BK, Allen S, Mays S, et al. Dynamic respiratory muscle function in late-onset Pompe disease. Sci Rep 2019;9:19006.

58. Wens SC, Ciet P, Perez-Rovira A, et al. Lung MRI and impairment of diaphragmatic function in Pompe disease. BMC Pulm Med 2015;15:54.

59. Gaeta M, Musumeci O, Mondello S, et al. Clinical and pathophysiological clues of respiratory dysfunction in lateonset Pompe disease: new insights from a comparative study by MRI and respiratory function assessment. Neuromuscul Disord 2015;25:852-8.

60. Laveneziana P, Albuquerque A, Aliverti A, et al. ERS statement on respiratory muscle testing at rest and during exercise. Eur Respir J 2019;53:1801214.

61. Reilly CC, Ward K, Jolley CJ, et al. Neural respiratory drive, pulmonary mechanics and breathlessness in patients with cystic fibrosis. Thorax 2011;66:240-6.

62. De Troyer A, Kirkwood PA, Wilson TA. Respiratory action of the intercostal muscles. Physiol Rev 2005;85:717-56.

63. Musumeci O, Ruggeri P, Montagnese F, et al. Breathing pattern and central ventilatory drive in late-onset Pompe disease. J Neuromuscul Dis 2015;2:S49.

64. van der Meijden JC, Güngör D, Kruijshaar ME, et al. Ten years of the international Pompe survey: patient reported outcomes as a reliable tool for studying treated and untreated children and adults with non-classic Pompe disease. J Inherit Metab Dis 2015;38:495-503.

65. Hagemans ML, van Schie SP, Janssens AC, et al. Fatigue: an important feature of late-onset Pompe disease. J Neurol 2007;254:941-5.

66. Boentert M, Karabul N, Wenninger S, et al. Sleep-related symptoms and sleep-disordered breathing in adult Pompe disease. Eur J Neurol 2015;22:369-76, e27.

67. Aboussouan LS. Sleep-disordered breathing in neuromuscular disease. Am J Respir Crit Care Med 
2015;191:979-89.

68. Aslan GK, Huseyinsinoglu BE, Oflazer P, et al. Inspiratory muscle training in late-onset Pompe disease: the effects on pulmonary function tests, quality of life, and sleep quality. Lung 2016;194:555-61.

69. Mellies U, Ragette R, Schwake C, et al. Sleep-disordered breathing and respiratory failure in acid maltase deficiency. Neurology 2001;57:1290-5.

70. Steier J, Jolley CJ, Seymour J, et al. Screening for sleepdisordered breathing in neuromuscular disease using a questionnaire for symptoms associated with diaphragm paralysis. Eur Respir J 2011;37:400-5.

71. Margolis ML, Howlett P, Goldberg R, et al. Obstructive sleep apnea syndrome in acid maltase deficiency. Chest 1994;105:947-9.

72. Bhui R, Spector AR. Obstructive sleep apnea in late-onset Pompe disease treated by enzyme replacement therapy. Neuromuscul Disord 2020;30:329-30.

73. Bach JR. Noninvasive respiratory management of patients with neuromuscular disease. Ann Rehabil Med 2017;41:519-38.

74. Cupler EJ, Berger KI, Leshner RT, et al. Consensus treatment recommendations for late-onset Pompe disease. Muscle Nerve 2012;45:319-33.

75. Pellegrini N, Laforet P, Orlikowski D, et al. Respiratory insufficiency and limb muscle weakness in adults with Pompe's disease. Eur Respir J 2005;26:1024-31.

76. Boentert M, Dräger B, Glatz C, et al. Sleep-disordered breathing and effects of noninvasive ventilation in patients with late-onset Pompe disease. J Clin Sleep Med 2016;12:1623-32.

77. Ambrosino N, Confalonieri M, Crescimanno G, et al. The role of respiratory management of Pompe disease. Respir Med 2013;107:1124-32.

78. Vianello A, Bevilacqua M, Arcaro G, et al. Prevention of pulmonary morbidity in patients with neuromuscular disorders: a possible role for permanent cricothyroid minitracheostomy. Chest 1998;114:346-7.

79. Chatwin M, Toussaint M, Goncalves MR, et al. Airway clearance techniques in neuromuscular disorders: a state of the art review. Respir Med 2018;136:98-110.

80. Finder JD, Birnkrant D, Carl J, et al. Respiratory care of the patient with Duchenne muscular dystrophy: ATS consensus statement. Am J Respir Crit Care Med 2004;170:456-65.

81. Silva IS, Pedrosa R, Azevedo IG, et al. Respiratory muscle training in children and adults with neuromuscular disease. Cochrane Database Syst Rev 2019;9:CD011711.
82. Jones HN, Crisp KD, Robey RR, et al. Respiratory muscle training (RMT) in late-onset Pompe disease (LOPD): effects of training and detraining. Mol Genet Metab 2016;117:120-8.

83. Wenninger S, Greckl E, Babačić H, et al. Safety and efficacy of short- and long-term inspiratory muscle training in late-onset Pompe disease (LOPD): a pilot study. J Neurol 2019;266:133-47.

84. Caruso P, Albuquerque AL, Santana PV, et al. Diagnostic methods to assess inspiratory and expiratory muscle strength. J Bras Pneumol 2015;41:110-23.

85. Toscano A, Schoser B. Enzyme replacement therapy in late-onset Pompe disease: a systematic literature review. J Neurol 2013;260:951-9.

86. Schoser B, Stewart A, Kanters S, et al. Survival and longterm outcomes in late-onset Pompe disease following alglucosidase alfa treatment: a systematic review and metaanalysis. J Neurol 2017;264:621-30.

87. Sharma R, Hughes D, Ramaswami U, et al. Enzyme replacement therapy for late-onset Pompe disease. Cochrane Database Syst Rev 2018;2018:CD012993.

88. Jezela-Stanek A, Chorostowska-Wynimko J, TylkiSzymańska A. Pulmonary involvement in selected lysosomal storage diseases and the impact of enzyme replacement therapy: a state-of-the art review. Clin Respir J 2020;14:422-9.

89. Schneider I, Hanisch F, Müller T, et al. Respiratory function in late-onset Pompe disease patients receiving long-term enzyme replacement therapy for more than 48 months. Wien Med Wochenschr 2013;163:40-4.

90. Stepien KM, Hendriksz CJ, Roberts M, et al. Observational clinical study of 22 adult-onset Pompe disease patients undergoing enzyme replacement therapy over 5years. Mol Genet Metab 2016;117:413-8.

91. Anderson LJ, Henley W, Wyatt KM, et al. Effectiveness of enzyme replacement therapy in adults with late-onset Pompe disease: results from the NCS-LSD cohort study. J Inherit Metab Dis 2014;37:945-52.

92. Strothotte S, Strigl-Pill N, Grunert B, et al. Enzyme replacement therapy with alglucosidase alfa in 44 patients with late-onset glycogen storage disease type 2: 12-month results of an observational clinical trial. J Neurol 2010;257:91-7.

93. Witkowski G, Konopko M, Rola R, et al. Enzymatic replacement therapy in patients with late-onset Pompe disease - 6-year follow up. Neurol Neurochir Pol 2018;52:465-9.

94. van der Meijden JC, Kruijshaar ME, Rizopoulos D, et 
al. Enzyme replacement therapy reduces the risk for wheelchair dependency in adult Pompe patients. Orphanet J Rare Dis 2018;13:82.

95. van der Ploeg AT, Clemens PR, Corzo D, et al. A randomized study of alglucosidase alfa in late-onset Pompe's disease. N Engl J Med 2010;362:1396-406.

96. Koeberl DD, Case LE, Desai A, et al. Improved muscle function in a phase I/II clinical trial of albuterol in Pompe disease. Mol Genet Metab 2020;129:67-72.

97. Byrne BJ, Geberhiwot T, Barshop BA, et al. A study on

Cite this article as: Shah NM, Sharma L, Ganeshamoorthy S, Kaltsakas G. Respiratory failure and sleep-disordered breathing in late-onset Pompe disease: a narrative review. J Thorac Dis 2020;12(Suppl 2):S235-S247. doi: 10.21037/jtd-cus-2020-007 the safety and efficacy of reveglucosidase alfa in patients with late-onset Pompe disease. Orphanet J Rare Dis 2017;12:144.

98. Pena LDM, Barohn RJ, Byrne BJ, et al. Safety, tolerability, pharmacokinetics, pharmacodynamics, and exploratory efficacy of the novel enzyme replacement therapy avalglucosidase alfa (neoGAA) in treatment-naïve and alglucosidase alfa-treated patients with late-onset Pompe disease: a phase 1, open-label, multicenter, multinational, ascending dose study. Neuromuscul Disord 2019;29:167-86. 